\title{
Spelling improvement through letter-sound and whole-word training in two multilingual Greek- and English- speaking children
}

\author{
Georgia Z Niolaki, Jackie Masterson ${ }^{*}$ and Aris R Terzopoulos
}

\author{
* Correspondence: \\ j.masterson@ioe.ac.uk \\ Institute of Education, University of \\ London, 25 Woburn Square, \\ London WC1H OAL, UK
}

\begin{abstract}
Case studies of two children with spelling difficulty are reported. LK was multilingual and ED bilingual. A training programme that targeted phonic decoding (or sublexical) spelling processes was conducted with both children. Immediate and delayed post-training assessments showed improvement in spelling nonwords for LK but not for ED. Training that targeted whole word (or lexical) spelling processes was then conducted with ED. Improvement in spelling of irregular words (a marker for lexical spelling processes) was observed. Research into literacy difficulties with multilingual children is sparse, although multilingualism is increasingly widespread. Up to now theoretically based training studies have focused on monolingual children and results were promising. The present findings indicate that theoretically based training programmes for literacy difficulties can also be effective for multilingual children.

Keywords: Multilingualism; Spelling training; Dual route model
\end{abstract}

\section{Introduction}

Interventions that aim at improving spelling of multiliterate children are important because $10 \%$ of the school age population throughout the European Union speak a different language at home than the majority one (Romaine 2004). Up to now literacy interventions have traditionally focused on reading skills in monolingual children (for example, Bradley and Bryant 1983; Stuart, 1999, 2004). Spelling intervention studies with monolingual children are far fewer (e.g., Brunsdon et al., 2005; Kohnen et al. 2008a, 2008b) and those including bilingual children are sparse, especially for bilinguals who acquire literacy in languages with different orthographies, such as English and Greek, which are the languages of the two children who are reported in the current paper.

The Greek and English writing systems differ in transparency of relationship between letters and sounds. English is more opaque than Greek for both reading and spelling. As we will see below Greek has inconsistent vowel sound-to-letter (or phonemegrapheme) correspondences, whereas English inconsistencies lie at the phonemegrapheme level but also at larger unit levels. Also, for English, there are thousands of phoneme-grapheme correspondences; while, for Greek, there are only a few, and 
importantly, for word endings, vowel spelling is morphologically determined (for example, verbs in first person singular present tense all end in $\langle\omega\rangle(/ \mathrm{o} /))$.

Researchers have carried out systematic analyses of the inconsistencies in the English writing system. For example, Kreiner (1992) calculated that $60 \%$ of written words have irregular spelling, and Ziegler et al. (1997) reported that $72 \%$ of monosyllabic words have inconsistent rimes. Other researchers have examined children's texts to calculate the level of inconsistency. For example, Stuart et al. (2003) analysed children's early reading vocabulary and found that $50 \%$ of the most frequent words are irregularly spelled. The major difficulty in English derives from the fact that one sound (or phoneme) can have many different correspondences, and these can consist of different graphemes, For example, the sound/i:/can be written as $\langle$ ee $\rangle,\langle\mathrm{i}\rangle,\langle\mathrm{ie}\rangle,\langle$ ea $\rangle$, etc. (for a comprehensive account see Dehaene, 2009). This high level of inconsistency might be expected to discourage use of phonological (or sublexical) strategies for reading and spelling and encourage more reliance on whole-word, visually based (or lexical) strategies. In support of this suggestion, Niolaki and Masterson (2012a) in a cross-linguistic study with monolingual seven-to-ten -year-old children reported that phonological ability (measured with a sound blending task) was strongly associated with spelling for Greek-speaking children, while both phonological ability and visual memory were associated with spelling for English-speaking children. The authors suggested that the level of transparency of the writing system leads to differential reliance on sound-based or whole-word visual processes for spelling.

Spencer (2007) tested 207 Year 2 to 6 UK pupils on the 120 most frequent words from a count of words in children's books, the Children's Printed Word Database (Masterson et al. 2003). He reported that printed word irregularity affected the pupils' spelling performance - sounds with many correspondences were harder to spell than those with few. Other characteristics, such as printed word frequency, were also associated with the children's spelling accuracy.

Turning to the characteristics of the Greek writing system, Harris and Giannouli (1999) point out that Greek spelling is based on the etymology of the words rather than their current pronunciation. Although Greek is highly transparent for reading (correspondences between graphemes and phonemes are almost 1:1), it is inconsistent for spelling. This is because the same vowel phoneme can be spelled with different graphemes - there are many words which contain different graphemes representing the phonemes/o/,/i/and/e/, since certain phonemic distinctions (e.g., between the vowels represented by $\langle\eta, \mathrm{l}, \mathrm{v}, \mathrm{ol}, \varepsilon \mathrm{l}, \mathrm{vl}>$ and those represented $\mathrm{by}<\mathrm{O}, \omega>$ or by $<\varepsilon, \alpha \mathrm{l}>$ ) are no longer present in the language. The prevalence of multisyllabic words with open syllabic structure (cvcvcv) in Greek means that children encounter the inconsistent vowel graphemes frequently. However, there are morphosyntactic rules which determine the correct vowel ending, so vowel spelling is not completely arbitrary. For instance, children learn that singular first person verbs end with the vowel grapheme $\langle\omega\rangle$ (e.g., $<\pi \alpha i \zeta-\omega>/$ pezo/(play)), while neuter singular nouns or adjectives take the

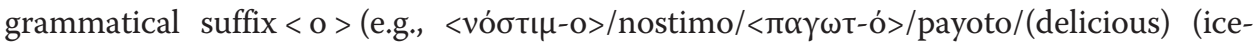
cream)).

However, things are not clear-cut when one considers the stem of the word, as stems cannot be correctly spelled on the basis of phonology or morphology only; word specific knowledge is also essential. Protopapas and Vlahou (2009)) calculated that the 
phoneme-grapheme ratio in Greek is 1.33, lower than the ratio for English which is estimated to be 1.7 (Caravolas, 2004).

According to Nikolopoulos et al. (2003) spelling difficulties for Greek children also stem from Greek being a highly inflected language. Consequently, an emergent literate has to learn many grammatical and syntactic rules, in order to master Greek spelling. Harris and Giannouli (1999) carried out a longitudinal study where they assessed spelling in nursery, then in Grade 1, Grade 2 and Grade 3. They concluded from their results that Greek children need at least three years of formal schooling, in order to master the basic morpho-syntactic rules.

Correct spelling in both English and Greek will depend on phonological, semantic and orthographic knowledge (Ehri, 1995; Perfetti and Hart, 2002; Romani et al. 2005). We also propose that visual memory capacity will play a role in languages with especially opaque orthographies, such as English, due to the inconsistencies of the spellings. The training programmes that we describe are based on these assumptions. Before we present the two case studies, the theoretical framework adopted will be outlined.

\section{Literature review}

Luria (1970, pp 323-324) described writing as a process involving different steps: 'The flow of speech is broken into individual sounds. The phonemic significance of these sounds is identified and the phonemes represented by letters. Finally, the individual letters are integrated to produce the written word'. Luria's 'phonic mediation theory' has been rendered untenable as cognitive neuropsychologists reported evidence of spelling without phonological mediation in cases of phonological dysgraphia (e.g., Shallice, 1981). Thus, it has been proposed that two procedures are necessary for skilled spelling (e.g., Barry, 1994; Ellis and Young, 1988). These are represented in Figure 1. One procedure is responsible for the retrieval of familiar and irregularly spelled words and is often referred to as the lexical route (Lex in Figure 1). This consists of a store (or lexicon) of auditory word recognition units, a word meaning store and a store of wholeword representations for written output (the orthographic output lexicon).

During spelling-to-dictation, in the case of familiar words, the presented word activates the phonological representation of the word (at auditory word recognition), this in turn activates the word's meaning (semantics) and the word's spelling in the orthographic output lexicon. Turning to the second of the two procedures, this has been termed sublexical or assembled, and is responsible for the correct spelling of novel, unfamiliar items and non-words. It entails parsing of the spoken input into its constituents (phonemes, syllables or other units), mapping the phonological units onto graphemic units, and finally assembling the units for output. This procedure will succeed with regular and pronounceable non-words but it will fail with irregular words, leading to phonologically plausible misspellings (e.g., light $\rightarrow$ LITE, $\varepsilon \kappa \kappa \lambda \eta \sigma i \alpha /$ eklisia/(church) $\rightarrow$ EK $\Lambda \mathrm{I} \Sigma I A$ ). Output from either the lexical or sublexical route is held in the graphemic buffer (which is a short-term memory store) until a written response or oral response is provided.

Researchers have studied spelling errors made by children as a means of providing information about the processes they use. Misspellings can be categorized as phonologically and non-phonologically appropriate in relation to the target word. A predominance of phonologically appropriate errors has been interpreted as indicating a reliance on 


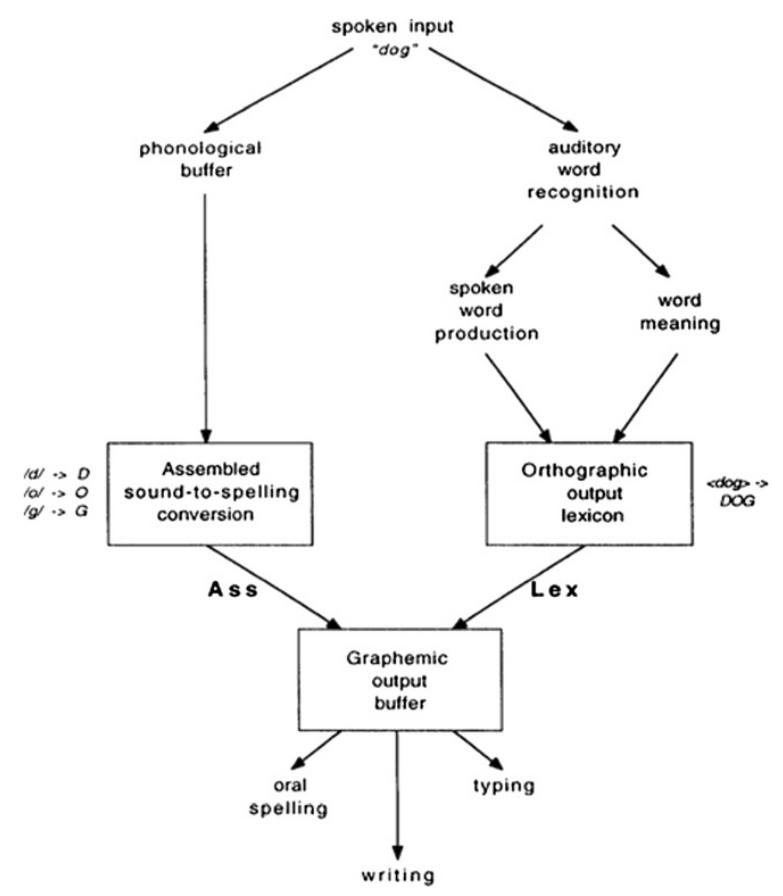

Figure 1 The dual route model for spelling (reproduced with permission Barry, 1994, pp.32).

the sublexical procedure due to a problem with lexical processes, whereas when errors are mainly phonologically inappropriate this has been interpreted as a difficulty with sublexical procedures.

Cross-linguistic group studies and case studies investigating spelling and reading skills with bilinguals suggest that difficulties manifested in one language will be evident in the second language as well (see, for example, Geva, 2000; Geva and Siegel, 2000). Klein and Doctor (1992) assessed a simultaneous bilingual child, KT, who had average intelligence but who was dyslexic in the two languages in which she was literate (Afrikaans and English). KT was assessed on reading words and nonwords in English and Afrikaans; she exhibited a severe difficulty with nonwords in both languages. Even though Afrikaans is a transparent language, her sublexical route was so compromised, that she was not able to take advantage of the transparency. Gupta and Jamal (2007) investigated a group of 30 bilingual dyslexic children (mean age 103 months) and compared their performance with that of a typically developing bilingual group (mean age 103 months). Children were assessed in reading words in Hindi and English. In Hindi, typically developing children made predominantly nonword errors while in English they made more real word substitutions, indicating that the transparency of Hindi led the children to rely on sublexical processes for reading, while the opaqueness of English led them to rely more on word-based processes. The situation was different in the case of the dyslexic children. They seemed to be unaffected by transparency and relied on sublexical processes for both languages. This is not an optimal strategy for English.

Intervention case studies and group studies with bilingual participants have also been reported. For example, Broom and Doctor (1995a) presented an intervention case study conducted with a bilingual 11-year-old boy SP. SP had developmental phonological 
dyslexia (particular difficulty with sublexical skills) and the intervention targeted phonological skills. Improvement in sublexical reading processes was found, and generalization occurred to untrained items. The researchers aimed at improving only his English reading ability and not his Afrikaans.

Stuart $(1999,2004)$ conducted an intervention group study with Reception and Year 1 children in London and the majority of the children were learning English as an additional language (EAL). An experimental group was administered a programme targeting phonological awareness and phonics, based on the Jolly Phonics scheme, and another group received a whole language programme, based on Holdaway's (1979) Big Books. The phonics programme was very effective for developing reading and spelling skills of the EAL and monolingual children and gains were sustained at the delayed post-intervention assessment at the end of Year 2. The same improvement was not detected for the Big Books intervention group. Comparisons revealed a 10-month reading age difference and an 11-month spelling age difference between the two groups in favour of the Jolly Phonics group. However, follow-up assessment at the end of Year 2 did not reveal a significant difference in reading comprehension scores between the two groups, indicating that a phonics programme is not enough to boost the children's comprehension skills.

\section{The present study}

We describe spelling intervention conducted with two school age children, LK and ED who were speakers of English and Greek. Testing began as soon as ethical approval was obtained from the Institute of Education, University of London Ethics Committee and as soon as letters of informed consent from parents and school authorities were returned. Although the children were receiving instruction in Greek and English, neither of them was making progress in spelling in either language. For LK the spelling intervention described below targeted both languages; whereas for ED only English spelling was targeted. Initially, a sublexical spelling intervention was administered for both children. The intervention was based on a study conducted by Brunsdon et al. (2002a). The researchers targeted sublexical reading processes of an eight-year-old boy who had mixed dyslexia. They aimed to teach grapheme-phoneme correspondences and to train grapheme segmentation and blending of phonemes. The intervention lasted four and a half months. Follow-up assessments conducted three months postintervention, indicated that grapheme-phoneme knowledge improved dramatically as well as reading of nonwords. In the present study, the sublexical intervention used aspects of Stuart's $(1999,2004)$ research (the Jolly Phonics scheme was adopted) and Clay's (1993) reading recovery programme (the writing procedure was used). Finally, from Hatcher's (1994) Sound Linkage programme the phonological ability teaching procedure was used.

To anticipate the outcome, at the end of the sublexical intervention and although LK's spelling was found to have improved, this was not the case for ED. A training targeting lexical spelling skills was administered next with ED. The intervention was based on previous training studies targeting lexical processes (such as those of Behrmann, 1987; Brunsdon et al., 2005; De Partz et al., 1992; Niolaki and Masterson 2012b; Weekes and Coltheart, 1996). Particularly, De Partz et al. (1992) used a visual imagery 
technique in a study with a 24-year-old male, LP, who had acquired surface dysgraphia. The intervention targeted irregular words using drawings embedded in words. LP's performance improved significantly. Behrmann (1987) used a technique linking homophone pairs with pictorial representations, in order to link orthography with semantics. Improvement was found for trained homophones and untrained irregular words but not for untrained homophones. Weekes and Coltheart (1996) using a pictorial mnemonic technique found improvement for treated but not untreated words.

Turning now to interventions with developmental dyslexics/dysgraphics, Brunsdon et al. (2005) conducted a study with a twelve- year-old child, MC, who had developmental surface dysgraphia. The intervention targeted the lexical route using techniques that had been successfully employed with acquired surface dyslexics (flashcards with and without mnemonic aids). Improvement in MC's irregular word spelling was found following a four-week training. For the mnemonic aid they reported that it did not produce a significant gain in comparison to a flashcard technique without mnemonics. The investigators found that untreated irregular words improved over the course of the intervention and many of these showed gradual improvement in degree of similarity to the correct spelling. Niolaki and Masterson (2012b), in an intervention study with a multilingual girl, NT, aged 10;03 with mixed dysgraphia, found that lexical training significantly improved spelling performance, and that flashcard and visual imagery techniques were equally effective. NT exhibited low levels of receptive vocabulary for English and Greek, and analysis of the gains made during intervention revealed that greater improvement was observed for known target words than unknown words for both languages.

We wanted to further examine whether interventions that have been found to be successful with monoliterate dysgraphic participants (Brunsdon et al. 2002a, 2002b; Brunsdon et al., 2005; Kohnen et al. 2008a, 2008b would achieve the same results with polyglot children. We aimed to examine which type of training would be more effective for these polyglot children with spelling difficulties and whether the intervention might result in improvement in reading as well as spelling, in accordance with findings from other intervention case studies (Brunsdon et al., 2005; Kohnen et al. 2008a, 2008b. For LK, who was biliterate, we investigated whether after the intervention targeting sublexical processes, he would produce more phonologically appropriate errors in spelling Greek than English, since this is the pattern that has been reported for children learning to read and spell in two alphabetic writing systems where one is more transparent than the other (c.f. Hagtvet and Lyster, 2003; Niolaki and Masterson 2012a).

\section{Case study: LK}

LK was a trilingual Greek-, English- and German-speaking boy, aged 7;03 when the assessment began in January 2010. LK's mother is Greek and his father is German and both languages are spoken at home. He was attending Grade 1 (the first year) of a Greek independent school in the UK, where children receive instruction in Greek language art, through the medium of Greek, for eight hours per week and English literacy, also through the medium of Greek, for ten hours per week. LK was a very sociable boy who fluently used English, Greek and German in his oral communication with adults and peers. The researcher who carried out the intervention was told by LK's parents 
and the Head Teacher that he had a fear of one-to-one tutorials. They explained that this fear derived from the fact that he could be stigmatised as having a difficulty. LK was indeed shy and resistant at the first meeting, however the researcher explained to him the reason why he was out of the class, how long it would last, and developed a very good rapport with LK. From then on he joined the one-to-one tutorials happily. LK was very enthusiastic about the support he received because he could observe the progress he was making, and this was also seen by his classroom teachers and peers.

At the school, formal teaching of English and Greek begins at the start of Grade 1 when children are 6 years old. Prior to this, children normally attend the Greek nursery, where the focus is on oral skills and some pre-literacy skills for both English and Greek. LK did not attend the Greek nursery. He had attended a local nursery prior to Grade 1 for two years that placed emphasis on physical education and learning through play. Formal teaching of English literacy was not included in their curriculum and at this point LK did not learn to read in English.

Table 1 gives the results of background assessments and tests of reading, spelling and phonological ability for English and Greek. Although LK was fluent in German, he was not literate in this language and was not receiving any instruction in German. Assessment of LK's spelling in English revealed that he could not spell his name correctly (he wrote only the first two letters) and he was not able to spell any high frequency words apart from the word at. He was only able to write in English the letters for the sounds/ $\mathrm{m} /, / \mathrm{a} /, / \mathrm{g} /, / \mathrm{t} / \mathrm{and} / \mathrm{s} /$. He made frequent letter reversals. In Greek he was able to spell his name and surname but there was not a clear discrimination among upper and lower case letters. He spelled just two high frequency words correctly ( $\mu \alpha \mu \alpha \dot{\alpha} / \mathrm{mama} /(\mathrm{mother})$ and óxı/ohi/(no)).

Table 1 Standardized scores in background assessments for LK and for the comparison group (scores in bold are for assessments where standardized scores were not available and represent percent correct)

\begin{tabular}{|c|c|c|}
\hline & LK & Comparison group mean \\
\hline Non-Verbal Reasoning ${ }^{a}$ & 96 & $105( \pm 23)$ \\
\hline Arithmetic ${ }^{\beta}$ & 100 & \\
\hline Verbal working memory ${ }^{c}$ & 95 & \\
\hline \multicolumn{3}{|l|}{ English measures } \\
\hline Spelling ${ }^{d}$ & 63 & \\
\hline Reading accuracy ${ }^{d}$ & 52 & \\
\hline Phonological ability ${ }^{e}$ & 95 & $114( \pm 20)$ \\
\hline Receptive Vocabulary ${ }^{f}$ & 106 & \\
\hline \multicolumn{3}{|l|}{ Greek measures } \\
\hline Spelling ${ }^{g}$ & 0 & $31.9( \pm 6.3)$ \\
\hline Reading accuracy ${ }^{g}$ & 0 & $98.6( \pm 1.5)$ \\
\hline Phonological ability ${ }^{\text {h }}$ & 70 & $119( \pm 18)$ \\
\hline Receptive Vocabulary ${ }^{i}$ & 66.6 & $43( \pm 26.7)$ \\
\hline
\end{tabular}

${ }^{a}$ Matrix Analogies Test, Naglieri (1985), ${ }^{\beta}$ WISC-IV, arithmetic subtest (Wechsler, 2003), ' WISC-IV, digit span subtest (ibid.), 'WIAT-II, Teacher's edition (Wechsler 2005), eblending subtest, CTOPP: Wagner et al. (1999), 'BPVS II (Dunn et al., 1997)

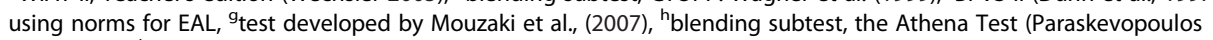
et al., 1999), 'PPVT-adapted for Greek (Simos et al., 2011). Scores in bold are for assessments where standardized scores were not available and represent percent correct. 
LK's phonological ability was assessed in English with the blending subtask of the Comprehensive Test of Phonological Processing (CTOPP, Wagner et al., 1999). His performance was age appropriate, but when he was assessed in a phoneme segmentation task and a phoneme deletion task from Hatcher's (1994) pre-intervention screening battery, his scores were 0 out of 6 correct, giving a standardized score of 36, and 1 out of 6, with a standardized score of 85 , respectively. Phonological ability in Greek was assessed with the blending subtest from the Athena Test (Paraskevopoulos et al., 1999). LK obtained a standardized score of 70 .

Standardised scores were not available for the Greek reading and spelling assessments and so LK's performance was contrasted with that of an age and non-verbal ability matched comparison group $(\mathrm{N}=6$, mean age $=7 ; 4$, s.d. $=.19)$. The comparison group consisted of bilingual Greek- and English-speaking children attending the same class at school as LK. Scores for the comparison group are also given in Table 1.

\section{Rationale for training}

It was decided to provide a training that aimed at improving LK's spelling skills since improvement in spelling as a result of training has been found to generalize to reading skill (Brunsdon et al., 2005; Conrad, 2008; Kohnen et al. 2008a, b; Ouellette, 2010), while the opposite has not been found to be the case (Perfetti, 1997). Additionally, spelling is a harder task than reading for both Greek and English orthographies. LK was towards the end of Grade 1 (in spring term- January to April) and he was not able to produce any writing, while children at this stage are typically able to write familiar and unfamiliar words to dictation and recognise the Greek letter-sounds. In English they are typically able to spell a pool of high frequency irregular words and they have been taught the letter sounds and names. Thus LK's teachers were concerned about his ability to cope in Grade 2. LK's sublexical skill was virtually non-existent in both languages, therefore it was decided that support for his letter-sound awareness and his decoding skills for spelling would be provided. Sublexical processes were chosen as the target since LK had not benefited from the phonics instruction he had received so far and it seemed important to put this skill in place before he moved on to Grade 2.

\section{Training programme}

The programme began in February 2010 and lasted for nine weeks. Sessions took place at LK's school, where the first author saw him individually for one hour per week. Sessions were divided into 30 minutes devoted to training in Greek and 30 minutes in English. Order of languages was alternated each week. The procedure adopted was the same for each session and a letter outlining what LK should do at home was given every week to his parents.

\section{Procedure}

The training included explicit teaching of phonics, following Hatcher's (1994) programme, it used the Jolly Phonics materials (Lloyd et al. 1992) and procedures used in Brunsdon et al. (2002a) intervention case study. The main difference between Brunsdon et al's study and ours is that they trained reading whereas spelling was targeted in the present study. Sessions began with assessment of letters taught the previous week (apart from the first session). Each week, six letters or digraphs were taught following the order of the Jolly 
Phonics scheme. Each letter was related to a word that LK sounded out and wrote, based on the procedure of Brunsdon et al. (2002a). For example, if the target letter was $U$, LK was presented with the letter written on a card and was asked to look at a card with a word beginning with that letter written on it (e.g., <up>). LK was asked to read and repeat the word three times, following the tester. Then he was asked to copy the letter, in upper and lower case, and the word. If he copied without error, then he was asked to write the word again after a ten second delay. This procedure was followed for each new letter/digraph.

The next part of each session included phonological activities, following Hatcher's (1994) Sound Linkage programme. The focus of the activities changed each week and included working on conceptualizing words as part of sentences, syllabic awareness, phoneme blending, phoneme discrimination and identification and transposition of phonemes.

Following the phonological activity in each session, LK was prompted to write one or more sentences (the structure of the sentence was subject-verb-object), incorporating sounds and words taught during the intervention. At this stage, following the method used in Reading Recovery intervention sessions (Clay, 1993), LK was asked to cut the sentence/s up into words, syllables and phonemes and then blend them, in order to reconstruct the words and finally the sentence/s. Then LK was asked to write the sentence again. Sometimes in the same session LK was also asked to construct the words using plastic letters placed in word boxes (Elkonin, 1971). The first author devised phonological activities in Greek equivalent to the ones just described.

At the end of each lesson a letter with directions and activities was given to LK's parents and they practiced with LK every day after school for twenty minutes. In this letter parents were advised to pronounce consonants without adding a vowel (for example, "sun" should be pronounced/s/,/u/,/n/, and not "suh" "u" "nuh"). They were also asked to use letter sounds and avoid using letter names as the training aimed to support phoneme-grapheme knowledge. Activities including the following were proposed: "Please ask LK to find the new letters in magazines to cut out and stick in his/her notebook. Please ask LK to cut out pictures with simple names that include the letter sound in different positions (beginning, middle and end). Under each picture he/she should try to write the name of the object in the picture. If he/she cannot write the word, you should help by saying it in a stretched out fashion. When LK finishes the activity he/she should read the words he/she has written. In that way LK will make his/her own sound book". Finally, directions regarding the teaching of the letters and sounds were given to the parents as follows:

1) Show a card with a letter on it to LK.

2) For each card LK should say the sound that the letter makes, not the name.

3) LK should say words which include the sound (at beginning, middle and end).

4) Remove the flashcard and ask LK to write the letter.

5) If LK cannot remember how to write the letter go back to step 1.

6) When LK can correctly sound out and write the letter move onto the next one.

This procedure had to be followed every day, and LK's parents were asked to practice all six letters/digraphs in the same way. 


\section{Post-training assessment}

Post-training assessments were conducted one week (sublexical post-test 1) and then four months (sublexical post-test 2) after the end of the training, in order to look for gains in spelling performance, and whether these were sustained over time. The tests that had been used prior to training for spelling, reading and phonological ability were employed. Results are given in Table 2 and indicate that LK showed improvement in spelling and reading for both English and Greek. He also showed improvement in phonological ability for Greek. In order to investigate whether effects of the training were specific to literacy and phonological processes, the arithmetic subtest from WISCIV was also re-administered immediately after the training. Scores showed no change (pre-training standard score $=100$, post-training standard score $=100$ ).

\section{Detailed investigation of spelling processes}

In order to investigate LK's spelling in more detail, his performance was examined in irregular and regular word and nonword spelling (tasks targeting lexical and sublexical spelling processes, respectively). Before the training LK had not been able to spell any of the irregular and regular words and nonwords. Table 3 presents his results following the training. The assessment was also administered to a group of age matched bilingual English- and Greek-speaking children $(\mathrm{N}=9)$ from LK's class at school. The comparison group had an average chronological age of 7;05 (s.d. =.29) years. The comparison children were tested at the same time as LK, that is, when he finished the training (immediate post-training assessment, sublexical post-test 1) and then four months later (delayed post-training assessment, sublexical post-test 2).

The results revealed that LK's sublexical skills, as reflected in nonword spelling, were better than lexical processes for both English and Greek. An advantage for nonword and regular spelling relative to irregular word spelling was also found for both languages in the comparison group ${ }^{1}$. Significant gains were also observed for reading accuracy for both Greek and English. The difference between the typically developing children and LK was not significant at the sublexical post-test 2 for English irregular word and nonword reading and for Greek word and nonword reading (for Greek the

Table 2 Pre-training, immediate and delayed post-training results for LK and comparison group performance (scores in bold are for assessments where standardized scores were not available and represent percent correct)

\begin{tabular}{lllll}
\hline & Pre-training & Immediate post-training & Delayed post-training & $\begin{array}{l}\text { Comparison } \\
\text { group mean }\end{array}$ \\
\hline English measures $^{\text {Spelling }}{ }^{a}$ & 63 & 79 & 87 & \\
Reading accuracy $^{a}$ & 52 & 75 & 79 & \\
Phonological ability $^{\beta}$ & 95 & 125 & 100 & \\
Greek measures & & & & $\mathbf{3 1 . 9 ( \pm 6 . 3 )}$ \\
Spelling $^{c}$ & $\mathbf{0}$ & $\mathbf{1 7}$ & $\mathbf{3 6 . 6}$ & $\mathbf{9 8 . 6 ( \pm 1 . 6 )}$ \\
Reading accuracy $^{\mathrm{c}}$ & $\mathbf{0}$ & $\mathbf{9 2}$ & $\mathbf{9 8 . 3}$ & $119( \pm 18)$ \\
Phonological ability $^{\mathrm{d}}$ & 70 & 95 & 125 & \\
\hline
\end{tabular}

aWIAT-II, Teacher's edition (Wechsler 2005), ${ }^{\beta}$ blending subtest, CTOPP: Wagner et al. (1999), 'test developed by Mouzaki et al. (2007), dblending subtest, Athena Test (Paraskevopoulos et al., 1999). 
Table 3 Percentage correct for LK and the comparison group in spelling and reading irregular and regular words and nonwords

\begin{tabular}{|c|c|c|c|c|c|}
\hline & \multirow[b]{2}{*}{ Pre-training } & \multicolumn{2}{|l|}{ LK } & \multicolumn{2}{|c|}{ Comparison group } \\
\hline & & $\begin{array}{l}\text { Immediate } \\
\text { post-training (T1) }\end{array}$ & $\begin{array}{l}\text { Delayed } \\
\text { post-training (T2) }\end{array}$ & $\mathrm{T} 1$ & T 2 \\
\hline \multicolumn{6}{|l|}{ English measures } \\
\hline Irregular spelling ${ }^{a}$ & 0 & 0 & 3.3 & $56( \pm 18.7)$ & $63( \pm 15.3)$ \\
\hline Regular spelling ${ }^{a}$ & 0 & 10 & 20 & $58.3( \pm 19.1)$ & $64( \pm 19.3)$ \\
\hline Nonword spelling ${ }^{a}$ & 0 & 17 & 30 & $71( \pm 17.1)$ & $81( \pm 7.1)$ \\
\hline Irregular reading ${ }^{a}$ & 0 & 0 & 30 & $57.2( \pm 22.7)$ & - \\
\hline Regular reading ${ }^{a}$ & 0 & 3.3 & 16.6 & $71.1( \pm 18.8)$ & - \\
\hline Nonword reading ${ }^{a}$ & 0 & 16.6 & 50 & $71.6( \pm 21.2)$ & - \\
\hline \multicolumn{6}{|l|}{ Greek measures } \\
\hline Irregular spelling ${ }^{\beta}$ & 0 & 5 & 15 & $32( \pm 9.9)$ & $49( \pm 14.5)$ \\
\hline Regular spelling ${ }^{\beta}$ & 0 & 35 & 55 & $81( \pm 15.9)$ & $85( \pm 8.6)$ \\
\hline Nonword spelling ${ }^{\beta}$ & 0 & 38 & 53 & $89( \pm 8.2)$ & $90( \pm 7.1)$ \\
\hline Real word reading ${ }^{\beta}$ & 0 & 42.5 & 87.5 & $95.8( \pm 5.6)$ & - \\
\hline Nonword reading ${ }^{\beta}$ & 0 & 50 & 95 & $98.3( \pm 2.04)$ & - \\
\hline
\end{tabular}

${ }^{a}$ DTWRP (Forum for Research into Language and Literacy 2012), ${ }^{\beta}$ List of irregular words and nonwords from Loizidou-leridou et al. (2009).

distinction between irregular and regular words does not exist for reading due to the high level of transparency).

\section{Qualitative analysis of spelling errors}

As noted in the introduction, researchers have studied the types of errors made in spelling as a means of investigating the processes being used. In a study using the same stimuli as the present one, and with children of similar age to LK, Niolaki and Masterson (2012a) reported that monolingual English-speaking children made 67\% phonologically appropriate errors and monolingual Greek-speaking children made $91 \%$ of such errors. We carried out qualitative analysis of the spelling errors made by LK. Inspection of the types of errors made in irregular word spelling at delayed-post intervention assessment revealed that the majority were phonologically appropriate (60\% for English and $88 \%$ for Greek).

\section{Discussion}

LK is a trilingual boy who showed severe difficulties in reading and spelling. Following training that targeted sublexical processes we observed improvement in spelling. This is in line with the findings of the training study carried out by Brunsdon et al. (2002a) using similar techniques with a monolingual child with mixed dyslexia. Improvement was also observed in LK's reading, in line with the findings of other studies targeting spelling (Brunsdon et al., 2005; Kohnen et al. 2008a, b). Assessment of LK's phonological skills revealed significant improvement in Greek, and this is likely due to the inclusion of this component in the training. Examination of performance in spelling irregular words and nonwords following the intervention showed an advantage for sublexical spelling processes. The lower level of attainment in irregular word spelling is 
likely due to the inconsistent nature of English and Greek for spelling. It might be that explicit teaching of whole word spellings, and many encounters with correct spellings are required to develop lexical skills (Bosman and van Orden, 1997; van Hell et al. 2003).

Qualitative analysis of spelling errors revealed that LK made more phonologically appropriate errors in Greek than in English. This is in accordance with other cross-linguistic studies of children learning English and another alphabetic but more transparent writing system. These studies have been conducted with both typically developing children (e.g., Niolaki and Masterson 2012b) and those with reading and spelling difficulties (e.g., Gupta and Jamal, 2007; Hanley et al. 2004).

\section{Case study: ED}

ED is a bilingual girl who was aged 7;09 when she was administered the background assessments. During the training only the one language in which she was literate, English, was targeted because her parents decided that improvement in English spelling skill was paramount. ED's mother tongue is Greek, but she was not literate in this language, although she attended a Greek afternoon school for five hours per week and was in Grade 1 when the assessment began. ED attended an English state school and was in Year 2. The first author was approached by ED's Greek literacy teacher who had concerns as ED was not showing any progress at all in Greek reading and spelling.

ED was a very sociable girl and she wanted to become an actress one day. During the lessons, according to her teachers, she had always contributed in discussions and confidently responded to oral questions. Prior to the intervention she did not like to write but she enjoyed very much reading aloud (although she guessed the words frequently) and presenting activities to the whole class. After and during the intervention she enjoyed writing stories and authoring her own books, albeit her writing was frequently illegible.

The results of background assessments, all in English, are given in Table 4. ED's scores in the non-standardised assessments were compared with those of a comparison group $(\mathrm{N}=7)$ matched to ED for age and nonverbal reasoning ability (mean age $=7 ; 6$, s.d. $=.40$ ). Children in the comparison group attended the same class in the afternoon Greek school as ED and they were all bilingual in English and Greek.

Inspection of the table reveals that ED scored at an average level in nonverbal reasoning. Receptive vocabulary, phonological ability and phonological working memory were low average. Further assessment of phonological ability with Hatcher's (1994) preintervention screening battery revealed that phoneme segmentation appeared to be unimpaired, with a standardised score of 106, but phoneme deletion was in the low average range, with a standardised score of 85 . Reading comprehension was at an average level. However, reading accuracy and spelling appeared to be impaired. This was manifested in reading and spelling of irregular words as well as nonwords.

Qualitative analysis of ED's spelling errors revealed that they were mainly phonologically inappropriate, for example, she spelt look $>$ LKII, candy $>$ CAD and under $>$ UND. She was able to spell three high frequency words up, sun and went. ED frequently confused $<$ a $>$ with $<$ e $>$ and she did not know the split digraph rule. ED usually accurately spelled first and last consonants (for example, half - HUF, street - SET). Her errors 
Table 4 Standardised scores in background assessments for ED and a comparison group (scores in bold are for assessments where standardized scores were not available and represent percent correct)

\begin{tabular}{|c|c|c|}
\hline & ED & Comparison group mean \\
\hline Non-Verbal Reasoning ${ }^{a}$ & 103 & $109.8( \pm 16)$ \\
\hline Arithmetic ${ }^{\beta}$ & 80 & \\
\hline Verbal working memory ${ }^{c}$ & 80 & \\
\hline Reading Comprehension ${ }^{d}$ & 110 & \\
\hline Spelling $^{d}$ & 74 & \\
\hline Reading accuracy ${ }^{d}$ & 72 & \\
\hline Phonological ability ${ }^{e}$ & 90 & \\
\hline Receptive vocabulary ${ }^{f}$ & 90 & \\
\hline Irregular word spelling ${ }^{g}$ & 0 & $48.3( \pm 26)$ \\
\hline Nonword spelling ${ }^{9}$ & 10 & $49.3( \pm 11)$ \\
\hline Irregular word reading ${ }^{9}$ & 23 & $70( \pm 20)$ \\
\hline Nonword reading ${ }^{9}$ & 20 & $70( \pm 26)$ \\
\hline
\end{tabular}

a Matrix Analogies Test, Naglieri (1985), ${ }^{\beta}$ WISC-IV, arithmetic subtest (Wechsler, 2003), ${ }^{c}$ WISC-IV, digit span subtest (ibid.), 'WIAT-II, Teacher's edition (Wechsler 2005), éblending subtest from CTOPP: Wagner et al. (1999), 'BPVS II (Dunn et al., 1997), using norms for EAL, 9DTWRP (Forum for Research into Language and Literacy 2012). Scores in bold are for assessments where standardized scores were not available and represent percent correct.

mainly involved vowel graphemes and she frequently omitted letters from clusters, and the letter $r$ (for example, street $>\mathrm{SET}$, dragon $>\mathrm{DIN}$, corner $>\mathrm{CON}$ ).

\section{Rationale for training}

It was decided to provide a sublexical training aimed at improving ED's spelling skills. ED was towards the end of Year 2 and her sublexical skill was very poor, based on her nonword spelling performance and high rate of phonologically inappropriate errors. Therefore, it was decided that support for sublexical skills for spelling would be provided. As for LK, it seemed important to put sublexical skills in place before ED moved on to the next school grade.

\section{Training programme}

The procedure and duration of the training were exactly the same as those followed for LK and described earlier. The programme began in February 2010 and lasted for nine weeks. A letter outlining the procedure was given to ED's parents (the letter was the same as the one provided to LK's parents, see Procedure section case study LK) and she practised every day at home for twenty minutes.

\section{Post-training assessment}

As with LK, post-training assessments were conducted one week (sublexical post-test 1) and then four months (sublexical post-test 2) after the end of the training. Results are given in Table 5. Inspection of the table reveals no change in performance in spelling and reading of nonwords.

\section{Interim discussion}

Although gains were found following the training in the standardized reading and spelling assessments, improvement in ED's sublexical skill was not observed. On the other 
Table 5 Scores for ED on assessments before training and following sublexical training

\begin{tabular}{llll}
\hline & Pre-Training & Immediate Post-sublexical training & Delayed Post-sublexical training \\
\hline Spelling $^{a}$ & 74 & 81 & 85 \\
Reading accuracy $^{a}$ & 72 & 88 & 82 \\
Phonological ability $^{\beta}$ & 90 & 95 & 95 \\
Irregular spelling $^{c}$ & $\mathbf{0}$ & $\mathbf{1 5}$ & $\mathbf{1 3 . 3}$ \\
Regular spelling $^{c}$ & $\mathbf{1 3}$ & $\mathbf{2 3}$ & $\mathbf{2 0}$ \\
Nonword spelling $^{c}$ & $\mathbf{1 0}$ & $\mathbf{1 3}$ & $\mathbf{1 0}$ \\
Irregular reading $^{c}$ & $\mathbf{2 3}$ & $\mathbf{2 3}$ & $\mathbf{3 0}$ \\
Regular reading $^{c}$ & $\mathbf{3 0}$ & $\mathbf{3 7}$ & $\mathbf{4 0}$ \\
Nonword reading $^{c}$ & $\mathbf{2 0}$ & $\mathbf{2 0}$ & $\mathbf{2 0}$ \\
\hline
\end{tabular}

${ }^{a}$ WIAT-II, Teacher's edition (Wechsler, 2005), ${ }^{\beta}$ blending subtest, CTOPP: Wagner et al. (1999), 'DTWRP (Forum for Research into Language and Literacy, 2012). Scores in bold are for assessments where standardized scores were not available and represent percentage correct.

hand, slight improvements in regular and irregular word spelling and regular word reading were apparent. Rapp et al. (2002) reported a case study of an acquired surface dysgraphic patient who made many phonologically plausible errors when spelling. The researchers found that the misspellings contained low probability phoneme-grapheme correspondences, which suggested interaction of lexical and sublexical processes. The errors could not be attributed to premorbid spelling, according to investigation of spelling performance prior to the dysgraphia. For typically developing children, Stuart and Masterson (1992) reported that children with good phonological skill at the outset of reading and spelling development had a larger sight vocabulary at age ten than children with poor pre-literacy phonological skills. Therefore, our results support the notion of a lexical and sublexical spelling model where lexical and sublexical processes are not totally independent. The current results also support findings from Brunsdon et al. (2002a) intervention study, although the researchers targeted reading and not spelling in their study. They found that although training targeted sublexical reading processes, improvement was observed in lexical reading processes (assessed by irregular word reading). Notwithstanding the improvements we observed, since gains were small, and not apparent in the case of nonword reading and spelling, a second intervention was designed, this time targeting lexical skills.

\section{Rationale for training}

ED had experienced three years of literacy instruction in primary school that focused on phonics, and her very poor sublexical skills did not seem to improve as a result of the phonics-based training programme that we provided. It was decided to conduct a lexical spelling intervention, since ED might benefit instead from a training that focused on establishing and strengthening orthographic representations. Brunsdon et al. (2002b) observed improvement using a lexical reading training in a child with mixed dyslexia who did not seem to benefit from an intensive four-year remediation programme focusing on "sounding out" words. The training put in place for ED was based on techniques (such as flashcard and visual imagery) used in previous studies (Brunsdon et al. 2002b; Brunsdon et al. 2005; Kohnen et al. 2008b that have targeted lexical processes. The difference between the aforementioned interventions and the one 
used in the present study was that ED had to devise the pictorial mnemonic herself and embed the misspelled part of the word in the picture.

\section{Training programme}

A ten-week programme was developed using whole-word based flash-card and visual imagery techniques, aimed at strengthening lexical processes (after Brunsdon et al. 2002b; Brunsdon et al., 2005; de Partz et al., 1992; Kohnen et al. 2008b; Niolaki and Masterson 2012b; Rowse and Wilshire, 2007; Weekes and Coltheart, 1996). The programme began two months after the delayed follow-up assessment conducted at the end of the sublexical training.

Before beginning the lexical training, two baseline assessments were carried out. The baseline assessments were conducted in November and December 2010. Words were taken from Masterson et al. (2008) and the regular and irregular word sets from the Diagnostic Test of Word Reading Processes (DTWRP, Forum for Research into Language and Literacy 2012). A total of 120 words were presented for spelling to dictation. In the DTWRP there are 30 regular words and 30 irregular words. The regular and irregular word sets were closely matched for printed word frequency (using values from the Children's Printed Word Database, Masterson et al., 2003), phonemes, letters and syllables (all $F s<1$ ). The word length per category ranged from 2 to 11 letters $($ mean $=6.4$, s.d. $=2.6)$ for regular words, and 3 to13 letters $($ mean $=6.3$, s.d. $=2.6)$ for irregular words. The second list of words used was the 60-word list of Masterson et al. (2008). Word length ranged from 3 to 11 letters (mean $=5.4$, s.d. $=1.6$ ). Word frequency values for the items were obtained from the Children's Printed Word Database (Masterson et al., 2003). The mean frequency was 198 (s.d. = 300).

The number of words misspelt was 92 at the first baseline assessment and 98 at the second. Performance did not differ significantly between the two $\left(\right.$ McNemar, $\chi^{2}(1)=$ $1.5, p=.22, \mathrm{r}=0.20)$. McNemar's test was used to analyse the data as we needed to analyse accuracy on the same words at two different time points - the data were therefore dichotomous and related (Field, 2009). From the words misspelt at both assessments $(\mathrm{N}=89) 60$ items were selected for the training. Low frequency words, such as sacrifice, were excluded. The 60 words were divided equally for use between the flashcard and visual imagery techniques. As in Brunsdon et al. (2005), the items included in the training sets each week were matched on number of orthographic neighbours (Kruskal Wallis: $\left.\chi^{2}(9)=4.5, p=.86\right)$, number of words that were regularly spelled $\left(\chi^{2}\right.$ (9) $=1.6, p=.99)$, printed word frequency $\left(\chi^{2}(9)=13.5, p=.14\right)$, and number of letters $\left(\chi^{2}(9)=5.7, p=.76\right)$. Kruskal Wallis test is the non-parametric equivalent of one-way independent measures ANOVA. Items were matched on the same variables across the visual imagery and flashcard training techniques (Kruskal Wallis: orthographic neighbours, $\chi^{2}(1)=.28, p=.59, \mathrm{r}=0.06$, number of words that were regularly spelled, $\chi^{2}(1)=.00, p=1$ $\mathrm{r}=0$, printed word frequency, $\chi^{2}(1)=.704, p=.83, \mathrm{r}=0.02$, and number of letters, $\chi^{2}(1)=.78$, $p=.37, \mathrm{r}=0.11$ ).

\section{Procedure}

In January, 2011, the lexical training began. At each of the weekly half-hour sessions, a new set of words was introduced. Half of the session was devoted to the imagery 
technique and half to the flashcard technique, with the order of techniques counterbalanced across sessions.

\section{Visual imagery technique}

The targeted word was shown to ED with the misspelt part highlighted in bold. ED was asked to think of a picture that depicted the word and to draw it with the word in view. She was then asked to embed the word in the picture (an example picture with embedded word is given in Figure 2). ED copied the picture with the embedded word, then the word was removed from view and after a delay of ten-seconds, ED reproduced the drawing with the embedded word. In the case of a spelling error, ED was asked to look again at the word and repeat the last activity. Finally, ED wrote the word to dictation without the picture.

\section{Flashcard technique}

The targeted word was first shown written on a card with the misspelt part highlighted. The tester wrote the word in large letters on an A4 card and ED traced it with her finger. Tracing was not included in the Brunsdon et al. (2005) intervention study. ED copied the word and it was then removed from view. After a ten-second delay, ED wrote the word again, dictated by the tester. In the case of an error, ED was asked to look at the word again and the process was repeated. Finally, ED wrote the target word to dictation.

ED practiced the items at home daily with her parents following the flashcard or visual imagery procedure, depending on the item. Practice lasted for 20 minutes per day, during which the target words were dictated to ED for spelling. When there was an error, ED looked at the word and wrote it again until accuracy was achieved. As in Brunsdon et al. (2005), at each weekly session with the researcher there was a re-test of items from the previous week. ED was not always $100 \%$ correct and the erroneously spelled words were not retrained.

\section{Post-training assessments}

Two post-training assessments were conducted, one month after the cessation of the intervention (lexical post-test 1) and four months later (lexical post-test 2). The tests that had previously been used to assess reading, spelling and phonological ability were employed. Irregular word and nonword reading and spelling to dictation were also

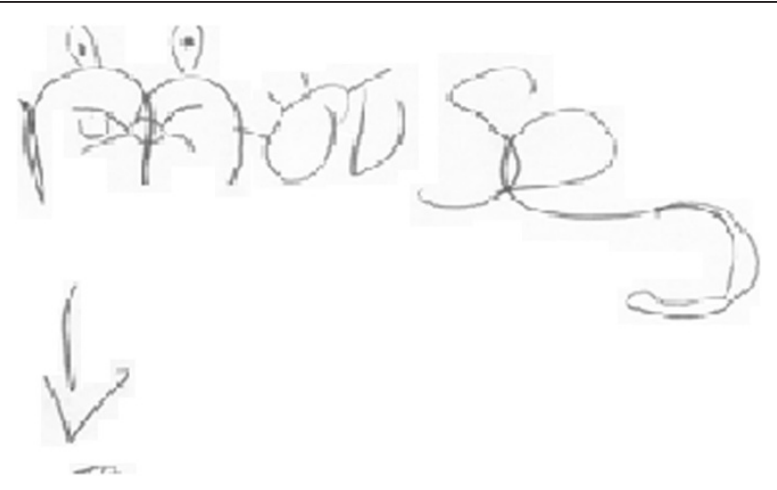

Figure 2 Example of a picture with an embedded word (mouse) used for the visual imagery technique. 
administered to a group of bilingual English- and Greek-speaking children $(\mathrm{N}=8)$ from ED's class at the Greek afternoon school. This comparison group had an average chronological age of 7;6 (s.d. =0.41). Results of the assessments are given in Table 6 . There was improvement in irregular word spelling (from 13.3\% correct before intervention to $38 \%$ correct at lexical post-test 1 ). The improvement was maintained since at lexical post-test 2 accuracy was still 33.3\%. ED also showed some improvement in irregular word reading (from 30\% before intervention to $37 \%$ and $50 \%$ at lexical post-test 1 and lexical post-test 2, respectively). There was also a substantial improvement in regular word spelling (an increase of 40\%), bringing ED's accuracy in line with that of the comparison children, although there was a decrease at lexical post-test 2 . There was a small improvement in nonword spelling, and gains in regular and irregular word reading that continued to increase to lexical post-test 2 . The level of accuracy for nonword reading was the same at lexical post-test 2 as before the intervention. The gains were thus largely in line with the focus of the training, that is, in lexical processes.

Accuracy in spelling the 60 trained words before and after training is plotted in Figure 3. There was a significant increase in spelling accuracy from baseline (number correct = $5 / 60)$ to lexical post-test 1 (number correct $=38 / 60)\left(\right.$ McNemar $\chi^{2}(1)=35.03, p=.000$, $\mathrm{r}=0.78$ ). Accuracy at lexical post-test 2 (number correct $=33 / 60$ ) was not significantly different from that at lexical post-test $1\left(\operatorname{McNemar} \chi^{2}(1)=3.3, p=.066, \mathrm{r}=0.25\right)$, indicating that improvement was sustained over time.

A comparison of the effectiveness of the visual imagery and flash card techniques was conducted. No difference in improvement was observed for the two (Kruskal Wallis, $p>.5$ ). ED was asked whether she had a preference for either technique. She reported that she liked both methods and that she thought they both helped with her spelling.

Analysis of possible generalization of the improvement to untrained words was carried out. Forty-three items that were misspelt in at least one of the two baseline assessments, but that were not included in the lexical training, were re-tested at lexical post-test 1 and 2. A significant improvement was observed between baseline (number correct =6) and

Table 6 Scores for ED on assessments before lexical training (Delayed Post-sublexical training) and following lexical training

\begin{tabular}{|c|c|c|c|c|c|}
\hline & \multirow[b]{2}{*}{$\begin{array}{l}\text { Delayed Post- } \\
\text { sublexical training }\end{array}$} & \multirow{2}{*}{$\begin{array}{l}E D \\
\text { Immediate Post- } \\
\text { lexical training }\end{array}$} & \multicolumn{3}{|c|}{ Comparison group mean } \\
\hline & & & $\begin{array}{l}\text { Delayed Post- } \\
\text { lexical training }\end{array}$ & T1 & $\mathrm{T} 2$ \\
\hline Spelling $^{a}$ & 85 & 92 & 90 & & \\
\hline Reading accuracy ${ }^{a}$ & 82 & 86 & 84 & & \\
\hline Phonological ability ${ }^{\beta}$ & 95 & 95 & 95 & & \\
\hline Irregular spelling ${ }^{c}$ & 13.3 & 38 & 33.3 & $48.3( \pm 26)$ & $55( \pm 20)$ \\
\hline Regular spelling ${ }^{c}$ & 20 & 60 & 47 & $61.4( \pm 20.2)$ & $64.2( \pm 18.2)$ \\
\hline Nonword spelling ${ }^{c}$ & 10 & 25 & 23.3 & $49.3( \pm 11)$ & $60( \pm 18)$ \\
\hline Irregular reading ${ }^{c}$ & 30 & 37 & 50 & $70( \pm 20)$ & - \\
\hline Regular reading $^{c}$ & 43 & 53 & 57 & $88( \pm 12.6)$ & - \\
\hline Nonword reading ${ }^{c}$ & 20 & 25 & 20 & $70( \pm 26)$ & - \\
\hline
\end{tabular}

${ }^{a}$ WIAT-II, Teacher's edition (Wechsler 2005), ${ }^{\beta}$ blending subtest, CTOPP: Wagner et al. (1999), 'DTWRP (Forum for Research into Language and Literacy 2012).

Scores for the comparison group are at Time 1 (end of ED's sublexical training) and Time 2 (end of ED's lexical training). Scores in bold are for assessments where standardized scores were not available and represent percentage correct. 


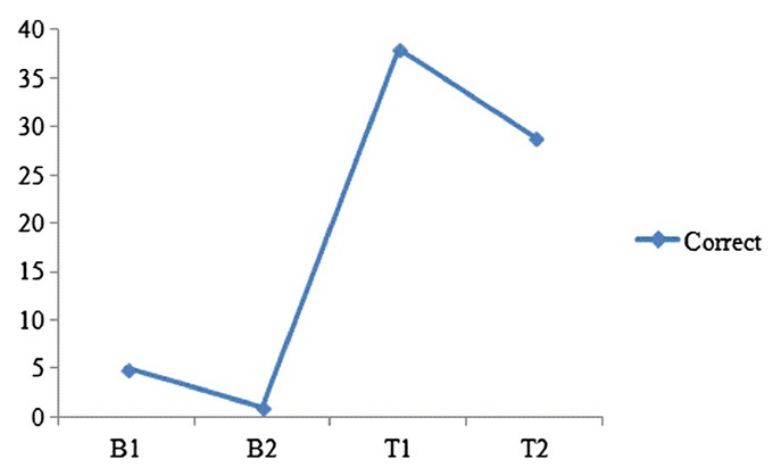

Figure 3 Accuracy in spelling the 60 items included in the intervention before and after the lexical/ sublexical training for ED. Note: $B=$ Baseline, $T=$ Time.

lexical post-test 1 (number correct $=16$ ), McNemar: $\chi^{2}(1)=7.5, p=.004, \mathrm{r}=0.45$, but not between lexical post-test 1 and lexical post-test 2 (number correct $=17$ ), $\chi^{2}(1)=0.0, p=1$, $\mathrm{r}=0.06$.

Analysis of the untrained words spelled correctly and incorrectly at lexical post-test 2 indicated that ED was more accurate with short and high frequency items (Mann-Whitney Test: $z=-3.3, p<.001, \mathrm{r}=0.32$ for letters and $z=-3.1, p=.002, \mathrm{r}=0.31$ for frequency). We used the Mann-Whitney Test to analyse the data as it is the non-parametric equivalent of the independent samples $t$-test and the data were not normally distributed. The finding corroborates the result obtained by Brunsdon et al. (2005) that the untrained words that are more likely to benefit from treatment, are high frequency ones.

Finally, in order to investigate the specificity of the effect of training, the arithmetic subtest from WISC-IV was administered before and immediately at the end of the lexical training. ED's score did not show any change (pre-training standard score $=80$, post-training standard score $=80$ ), indicating that the effect of the training was specific to literacy processes.

\section{Discussion}

Following the lexical training improvement in spelling for irregular words, as well as generalization to untrained words, was observed. Both flashcard and visual imagery techniques were found to be effective. The results are in accordance with other training studies targeting lexical processes (e.g., Behrmann, 1987; Brunsdon et al., 2005; De Partz, et al., 1992; Kohnen et al. 2008b; Niolaki and Masterson 2012b). Although a difference in effectiveness of the flashcard and visual imagery techniques was not observed in the present study, one might have been found, if the strategies had been used at different times in the training. Further research looking at the two strategies could shed more light on this.

\section{General discussion}

The present study aimed at improving spelling in two multilingual children. Intervention case studies with multilingual children are sparse. Also research has tended to focus on reading skill rather than spelling. Spelling is a stumbling block in literacy acquisition for children learning English and Greek. Consequently, it was considered important to investigate how spelling skills can be improved in polyglot children. 
LK, a seven-year-old trilingual boy literate in Greek and English, had spelling difficulties in both languages, although he had had more than two terms of formal literacy instruction targeting phonic skills. His phonological ability in Greek and English (at least as assessed by Hatcher's, 1994, tasks) seemed to be underdeveloped. As LK could not write any novel items and his knowledge of phoneme-grapheme correspondences was very poor we devised a sublexical training program.

LK's sublexical spelling showed improvement, especially in Greek, and the change was shown to be sustained at delayed post-testing four months after the programme ceased. LK's higher level of accuracy for spelling nonwords in Greek compared to English following the intervention might have to do with the characteristics of the Greek writing system (being more transparent than English), or with the fact that LK attended a Greek medium school where children spoke more Greek than English. The training involved the explicit teaching of phoneme-grapheme correspondences and phonological skills. The effect of the training appeared to generalize to reading, in accordance with previous findings from single case intervention studies involving both lexical and sublexical training techniques (Brunsdon et al., 2005; Conrad, 2008; Kohnen et al. 2008a, b).

ED was a seven-year-old emergent bilingual, literate only in English, who was found to have poor irregular word and non-word spelling and reading, indicating difficulty with both lexical and sublexical processes. Assessment of phonological ability revealed a standardized score in the average range of 95 but assessment of verbal working memory revealed a standard score of 80 . ED took part in a training targeting sublexical processes, as we wanted to strengthen her sublexical skills; however, this training did not result in improvement, perhaps due to ED's verbal memory difficulty. A second training programme was administered targeting lexical processes.

The lexical training resulted in improvement in spelling for targeted words, and also for untrained items. Interventions involving repeated exposure to correct spellings using flashcard techniques and delayed coping have been found to be effective, presumably because they lead to strengthening of orthographic representations (e.g., Rapp and Kane, 2002 for evidence from acquired dysgraphia; Brunsdon et al., 2005 and Kohnen et al. 2008b for evidence from developmental dysgraphia). ED's spelling of nonwords was also observed to improve slightly; however, nonword reading did not improve. ED showed improvement in irregular word reading that continued after the cessation of the lexical intervention, although the training had targeted only spelling. Similarly, LK improved in all reading tasks after the end of the sublexical intervention and in both languages. Thus, for both children it appeared that generalisation to reading skill took place, and this is in accordance with other treatment case studies conducted with monoliterate children (e.g. Brunsdon et al., 2005; Conrad, 2008; Kohnen et al. 2008a, b). Further research investigating transfer effects of training will be informative.

Overall, for both LK and ED, training produced improvement in spelling, and for LK improvement was observed in both languages in which he was literate. As such, the results provide further confirmation that the dual route model of spelling can be a useful theoretical framework for specifying the locus of the difficulty in children with spelling deficits and for implementing training (e.g., Brunsdon et al., 2005). Kohnen et al. (2008a, 2008b, 2010) argue that intervention success and generalization is largely dependent on the pre-training performance of the participant and intervention should be tailored on the basis of this performance. If the assessments indicate a phonological 
deficit, this may suggest that a training targeting the sublexical route will be effective, as was found to be for LK. For ED, on the other hand, although the sublexical training seemed to result in some improvement as reflected in the standardized spelling assessment, it was not effective in improving sublexical skills. Instead ED showed improvement in lexical skills following training that targeted whole words. It could be that ED would have shown improvement if the sublexical intervention had been of longer duration. The training in Brunsdon et al. (2002a) sublexical intervention study lasted for four and a half months, whereas ours lasted just nine weeks. Further research is needed to specify the circumstances under which different types of training are effective.

The finding that ED showed a small improvement in irregular word spelling following the first intervention, even though it targeted only sublexical processes, could be also explained by the triangle model (Plaut, 2005). There is no specific process in the model that deals only with irregular words or nonwords. As the model develops, the semantic pathway deals more with reading and spelling of irregular words and the phonological pathway with consistently read and spelt words. According to Coltheart (2005) and Rapp et al. (2002) the triangle model also includes two different processes, a direct one via semantics for real word reading and an indirect one via phonology for nonword reading. The major difference in comparison to the DR model is that the sublexical system can also generate accurate pronunciations for irregular high frequency items. Therefore, the triangle model allows for interaction between the two spelling processes. Thus, the improvement of irregular spelling, although intervention targeted sublexical processes, could relate to this assumption of a phonological route that generates accurate spelling of irregular words.

It is also important to consider another issue related to language characteristics. According to a by now well-established body of research it is apparent that the properties of individual languages determine the characteristics of literacy difficulties. As both of LK's languages were opaque for spelling his difficulty was manifested in both Greek and English. Results are in accordance with those of Geva (2000) who claims that a deficit in literacy development will be apparent in both languages. However, this may not be the case for biliterates who use very different writing systems (c.f., Wydell and Kondo, 2003).

Finally, both LK and ED were motivated to participate in their intervention due to the fact that someone was supporting them in their efforts to achieve what the other children seemed to be achieving effortlessly. Dehaene (2009) and others have stressed the importance of keeping children motivated and engaged during the intervention. The case studies add to research into literacy difficulties in bilingual children. However, further intervention studies are needed in order to increase our knowledge of which methods are optimum for remediating spelling deficits. Most important is the implementation of early intervention, in order to reduce the number of children falling behind in spelling and writing, and to provide more consideration in teaching of spelling as a valuable aspect of literacy acquisition.

\section{Consent}

Written informed consent was obtained from the parents for the publication of this report and any accompanying images. 


\section{Endnote}

${ }^{1}$ The Loizidou et al. and DTWRP items are not matched on variables such as printed word frequency, word length etc., so direct comparison of levels of accuracy is problematic.

\section{Competing interests}

The authors declare that they have not competing interests.

\section{Authors' contributions}

Authors GN and AT collected and analysed the data. Authors GN, JM and AT drafted the manuscript. All authors read and approved the final manuscript.

\section{Acknowledgements}

The research was supported in part by a Central Research Fund Grant, European Scholarship, the Onassis and Leventis Foundations and Wingate Scholarship awarded to the first author and a European Scholarship awarded to the third author. The authors are grateful to the teachers, staff, parents and children of participating schools.

\section{Received: 27 October 2013 Accepted: 31 July 2014}

Published: 21 August 2014

\section{References}

Barry, C. 1994. Spelling Routes (or Roots or Rutes). In Handbook of Spelling. Theory, Process and Intervention, ed. GDA Brown and NC Ellis, 27-49. West Sussex: John Wiley and Sons Ltd.

Behrmann, M. 1987. The rites of righting writing: Homophone remediation in acquired dysgraphia. Cognitive Neuropsychology 4:365-384.

Bosman, AMT, and GC Van Orden. 1997. Why spelling is more difficult than reading. In Learning to spell: Research, Theory and practice across languages, ed. CA Perfetti, L Rieben, and M Fayol, 173-194. Hillsdale, NJ: Lawrence Erlbaum Associates.

Bradley, L, and PE Bryant. 1983. Categorizing sounds and learning to read-a causal connection. Nature 301:419-421.

Broom, YM, and E Doctor. 1995. Developmental phonological dyslexia: a case study of the efficacy of a remediation programme. Cognitive Neuropsychology 12:725-766.

Brunsdon, R, TJ Hannan, L Nickels, and M Coltheart. 2002a. Successful treatment of sublexical reading deficits in a child with dyslexia of a mixed type. Neuropsychological Rehabilitation 12:199-229.

Brunsdon, R, TJ Hannan, M Coltheart, and L Nickels. 2002b. Treatment of lexical processing in mixed dyslexia: A case study. Neuropsychological Rehabilitation 12:385-418.

Brunsdon, R, M Coltheart, and L Nickels. 2005. Treatment of irregular word spelling in developmental surface dysgraphia. Cognitive Neuropsychology 22:213-251.

Caravolas, M. 2004. Spelling development in alphabetic writing systems: A cross-linguistic perspective. European Psychologist 9:3-14.

Clay, M. 1993. An observation survey of early literacy achievement. Portsmouth, NH: Heinemann.

Coltheart, Max. 2005. Modeling Reading: The Dual-Route Approach. In The Science of Reading, A Handbook, ed. Margaret I Snowling and Charles Hulme, 6-23. Oxford: Blackwell Publishing.

Conrad, NJ. 2008. From reading to spelling and spelling to reading: Transfer goes both ways. Journal of Educational Psychology 100:869-878.

De Partz, M-P, X Seron, and M Van Der Linden. 1992. Re-education of a surface dysgraphia with a visual imagery strategy. Cognitive Neuropsychology 9:369-401.

Dehaene, Stanislas. 2009. Reading in The Brain. London: Penguin Viking

Dunn, LM, LM Dunn, C Whetton, and J Burley. 1997. British Picture Vocabulary Scale 2nd edition (BPVS-II). Windsor, Berks: NFER-Nelson.

Ehri, LC. 1995. Phases of development in learning to read by sight. Journal of Research in Reading 18:116-125.

Elkonin, D. 1971. Development of Speech. In The psychology of pre-school children, ed. AV Zaporozhets and DB Elkonin, 225-251. Cambridge, MA: M.IT. Press.

Ellis, AW, and AW Young. 1988. Human Cognitive Neuropsychology. East Sussex: LEA Ltd.

Field, Andy. 2009. Discovering statistics using SPSS. London: Sage.

Forum for Research into Language and Literacy. 2012. Diagnostic Test of Word Reading Processes (DTWRP). London: GL Assessment.

Geva, E. 2000. Issues in the assessment of reading disabilities in L2 children: Beliefs and research evidence. Dyslexia 6:13-28.

Geva, E, and L Siegel. 2000. Orthographic and cognitive factors in the concurrent development of basic reading skills in two languages. Reading and Writing: An Interdisciplinary Journal 12:1-30.

Gupta, A, and G Jamal. 2007. Reading strategies of bilingual normally progressing and dyslexic readers in Hindi and English. Applied Psycholinguistics 28:47-68.

Hagtvet, B, and S-A Lyster. 2003. The spelling errors of Norwegian good and poor decoders: a developmental cross-linguistic perspective. In Dyslexia in different languages. Cross-linguistic comparisons, ed. N Goulandris, 181-207. London: Whurr Publishers.

Hanley, JR, J Masterson, L Spencer, and D Evans. 2004. How long do the advantages of learning to read a transparent orthography last? An investigation of the reading skills and reading impairment of Welsh children at 10-years of age. The Quarterly Journal of Experimental Psychology 57:1393-1410. 
Harris, M, and V Giannouli. 1999. Learning to read and spell in Greek: the importance of letter knowledge and morphological awareness. In Learning to read and write: A cross-linguistic perspective, ed. M Harris and G Hatano, 51-69. Cambridge: University Press.

Hatcher, PJ. 1994. Sound linkage: An integrated programme for overcoming reading difficulties. London: Whurr Publishers Ltd.

Holdaway, D. 1979. The foundations of Literacy. Sydney, NSW: Ashton Scholastic.

Klein, D, and EA Doctor. 1992. Phonological processing in bilingual word recognition. In Cognitive Processing in Bilinguals, ed. RJ Harris, 237-252. Amsterdam: Elsevier Science Publishers B.V.

Kohnen, S, L Nickels, R Brunsdon, and M Coltheart. 2008a. Patterns of generalization after treating sub-lexical spelling deficits in a child with mixed dysgraphia. Journal of Research in Reading 31:157-177.

Kohnen, S, N Nickels, M Coltheart, and R Brunsdon. 2008b. Predicting generalization in the training of irregular-word spelling: Treating lexical spelling deficits in a child. Cognitive Neuropsychology 25:343-375.

Kohnen, S, L Nickels, and M Coltheart. 2010. Training rule-of-E: Further investigation of a previously successful intervention for a spelling rule in developmental mixed dysgraphia. Journal of Research in Reading 33:392-413.

Kreiner, DS. 1992. Reaction time measures of spelling: Testing a two-strategy model of skilled spelling. Journal of Experimental Psychology: Learning, Memory and Cognition 18:765-776.

Lloyd, S, S Wernham, and C Jolly. 1992. Jolly Phonics. Essex: Jolly Learning.

Loizidou-leridou, N, J Masterson, and JR Hanley. 2009. Spelling development in 6-11year-old Greek-speaking Cypriot children. Journal of Research in Reading 33:247-262.

Luria, AR. 1970. Traumatic Aphasia. The Hague: Mouton.

Masterson, J, M Stuart, M Dixon, and S Lovejoy. 2003. Children's printed word database (CPWD). Available at http://www.essex.ac.uk/psychology/cpwd/documents/CPWD\%20manual.pdf accessed 16th of March 2009.

Masterson, J, L Colombo, K Spencer, K Ftika, and A Syntili. 2008. Factors affecting spelling of English- and Greekspeaking Grade 1 and 2 children. London: Presented at the 1st Writing Systems Conference, Institute of Education.

Mouzaki, A, A Protopapas, P Sideridis, and G Simos. 2007. Psychometric properties of a new test of spelling

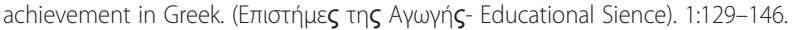

Naglieri, JA. 1985. Matrix Analogies Test (short form) (MAT-SF). New York: The psychological cooperation Harcourt Brace Jovanovich, INC.

Nikolopoulos, D, N Goulandris, and Margaret Snowling. 2003. Developmental dyslexia in Greek. In Dyslexia in different languages cross-linguistic comparisons, ed. Nata Goulandris, 53-67. London: Whurr Publishers.

Niolaki, Georgia, and Jackie Masterson. 2012a. Transfer effects in spelling from transparent Greek to opaque English in seven- to nine-year-old children. Bilingualism: Language and Cognition 15:757-770.

Niolaki, G, and J Masterson. 2012b. Intervention for a spelling difficulty in a trilingual child, L3 conference. Spain: Castellon. 2012.

Ouellette, G. 2010. Orthographic learning in learning to spell: The roles of semantics and type of practice. Journal of Experimental Child Psychology 107:50-58.

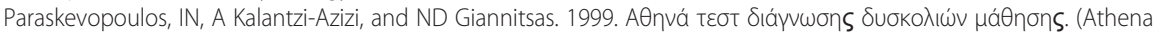
Test: Diagnosis of Learning Difficulties). Athens: Ellinika Grammata.

Perfetti, CA. 1997. The psycholinguistics of spelling and reading. In Learning to Spell: Research, Theory, and Practice Across Languages, ed. CA Perfetti, L Rieben, and M Fayol, 21-38. London: Laurence Erlbaum Associates, Inc.

Perfetti, CA, and L Hart. 2002. The lexical quality hypothesis. In Precursors of Functional Literacy, ed. L Vehoeven, C Elbro, and P Reitsma, 189-213. Amsterdam/Philadelphia: John Benjamins.

Plaut, David C. 2005. Connectionist Approaches to Reading. In The Science of Reading, A Handbook, ed. Margaret J Snowling and Charles Hulme, 24-38. Oxford: Blackwell Publishing.

Protopapas, A, and EL Vlahou. 2009. A comparative quantitative analysis of Greek orthographic transparency. Behavioural Research Methods 41:991-1008

Rapp, B, and A Kane. 2002. Remediation of deficits affecting different components of the spelling process. Aphasiology 16:439-454.

Rapp, B, C Epstein, and MJ Tanturier. 2002. The integration of information across lexical and sublexical processes in spelling. Cognitive Neuropsychology 19(1):1-29.

Romaine, S. 2004. The bilingual and multilingual community. In The Handbook of Bilingualism, ed. TK Bhatia and WC Ritchie, 385-405. Malden, MA: Blackwell.

Romani, C, A Olson, and AM Di Betta. 2005. Spelling Disorders. In The Science of Reading, A Handbook, ed. MJ Snowling and C Hulme, 431-449. Oxford: Blackwell.

Rowse, HJ, and CE Wilshire. 2007. Comparison of phonological and whole-word treatments for two contrasting cases of developmental dyslexia. Cognitive Neuropsychology 24:817-842.

Shallice, T. 1981. Phonological agraphia and the lexical route in writing. Brain 104:413-429.

Simos, PG, GD Sideridis, A Protopapas, and A Mouzaki. 2011. Psychometric evaluation of a receptive vocabulary test for Greek elementary students. Assessment for Effective Intervention 37:34-49.

Spencer, K. 2007. Predicting children's word-spelling difficulty for common English words from measures of orthographic transparency, phonemic and graphemic length and word frequency. British Journal of Psychology 98:305-338.

Stuart, M. 1999. Getting ready for reading: Early phoneme awareness and phonics teaching improves reading and spelling in inner-city second language learners. British Journal of Educational Psychology 69: 587-605.

Stuart, M. 2004. Getting ready for reading: A follow-up study of inner city second language learners at the end of Key Stage I. British Journal of Educational Psychology 74:15-36.

Stuart, M, and J Masterson. 1992. Patterns of reading and spelling in 10-year-old children related to pre-reading phonological abilities. Journal of Experimental Child Psychology 54:168-187.

Stuart, M, M Dixon, J Masterson, and B Gray. 2003. Children's early reading vocabulary: Description and word frequency lists. British Journal of Educational Psychology 73:585-598. 
van Hell, JG, AMT Bosman, and MCS Bartelings. 2003. Visual dictation improves the spelling performance of three groups of Dutch students with spelling disabilities. Learning Disability Quarterly 26:239-255.

Wagner, RK, JK Torgesen, and CA Rashotte. 1999. Comprehensive Test of Phonological Processes. Austin: PRO-ED Publishing, Inc.

Wechsler, D. 2003. Wechsler Intelligence Scale for Children - Fourth UK Edition (WISC-IV UK). London: Harcourt Assessment.

Wechsler, D. 2005. Wechsler Individual Achievement Test - Second UK Edition (WIAT-II UK). London: Harcourt Assessment.

Weekes, B, and M Coltheart. 1996. Surface dyslexia and surface dysgraphia: Treatment studies and their theoretical implications. Cognitive Neuropsychology 13: 277-315.

Wydell, TN, and T Kondo. 2003. Phonological deficit and the reliance on orthographic approximation for reading: a follow-up study on an English-Japanese bilingual with monolingual dyslexia. Journal of Research in Reading 26:33-48.

Ziegler, C, GO Stone, and AM Jacobs. 1997. What is the pronunciation for -ough and the spelling for lui? A database for computing feedforward and feedback Consistency in English. Behavior Research Methods, Instruments, and Computers 29:600-618.

doi:10.1186/s13616-014-0020-3

Cite this article as: Niolaki et al: Spelling improvement through letter-sound and whole-word training in two multilingual Greek- and English- speaking children. Multilingual Education 2014 4:20.

\section{Submit your manuscript to a SpringerOpen ${ }^{\circ}$ journal and benefit from:}

- Convenient online submission

- Rigorous peer review

- Immediate publication on acceptance

- Open access: articles freely available online

- High visibility within the field

- Retaining the copyright to your article

Submit your next manuscript at $\boldsymbol{~ s p r i n g e r o p e n . c o m ~}$ 